Oralidad-es

REVISTA DE LA RED IBEROAMERICANA DE ESTUDIOS

SOBRE ORALIDAD

\title{
Editorial volumen 4 Oralidad-es. Tras algunos descentramientos
}

\author{
Mónica María del Valle \\ monicalatraductora@gmail.com \\ Universidad de La Salle, Colombia
}

Del Valle, M. M. (2018). Editorial volumen 4 Oralidad-es. Tras algunos descentramientos. Oralidad-es, 4, 1-4. https://revistaoralidad-es.com/index.php/ro-es/article/view/93/66 
La vastedad de las manifestaciones de la oralidad es desbordante. El título de esta revista y el trabajo de acopio que ha venido haciendo durante los años lo prueban, pues cada nueva entrega es un asedio que no puede, ni podría, cubrir la casi insondable diversidad que tiene ante sí. Este número no es una excepción. Nuestra convocatoria a intelectuales en general era a enviar contribuciones en torno a la oralidad en una perspectiva cultural amplia, no circunscrita al aula de clase ni a los abordajes lingüísticos, preferiblemente centradas en la especificidad del contexto colombiano. Los artículos que componen el número rondan esta invitación cada uno en su propia dimensión. Privilegiar este encuadre nos permitía insistir en que el estudio de la oralidad nos obliga a des-encuadres o des-ajustes epistemológicos, nos formula preguntas sobre lo que hemos considerado lícito como conocimiento: qué conocemos, cómo se produce y qué función tiene, cómo lo desentrañamos. Es en esta dimensión "cultural", donde el concepto "oralidad" revela las tensiones en que se encuentra, las relaciones de poder (con la escritura, con lo considerado aprendible y enseñable y con las autoridades a quienes se les permite esa transmisión) donde libra su batalla. Los artículos que conforman este número abordan esas cuestiones con insistencia, tácita o explícitamente, y nos entregan un lente para fijar la problemática. El texto de Luis Carlos Castro Ramírez, "El decir-hacer en una ceremonia de Olokun" recompone una ceremonia iniciática en el contexto de la espiritualidad santera. Castro Ramírez es uno de los académicos más conocedores del campo de las religiones afro contemporáneas en Colombia y en los lugares de los que llegaron al país por fenómenos como el narcotráfico. De manera que aunque este trabajo da cuenta de una ceremonia realizada en Cuba. Su trabajo es mostrarnos cómo funciona lo que en otros campos teóricos se denomina el performance de la religión y su texto nos resulta indispensable en la medida en que no solo nos acerca a la intimidad de una ceremonia de Olokun, sino que además nos plantea preguntas complejas sobre cómo este mundo de lo afroespiritual ha digerido e incorporado cruces históricos importantes, así como porque revela el nivel de sofisticación de este conocimiento performado, articulado sobre la iniciación. El primer desencuadre tiene que ver entonces con la noción de conocimiento válido, el terreno en el que ese conocimiento actúa (lo espiritual) y los mecanismos de transmisión y de interpretación del mismo. "Territorios corp-orales, completos y pluriversos: una perspectiva para comprender para el arte y la transformación", nos empuja al centro de un debate sobre conocimientos localizados (para este caso, los conocimientos producidos en geografías racializadas como el Chocó), pero en especial, sobre las definiciones del "arte" en terrenos convencionalmente dejados por fuera de dicha noción. Uno de los proyectos más interesantes, a mi parecer, en el actual contexto de las poblaciones etnizadas en Colombia es el de la Corp-oraloteca de la Universidad Tecnológica del Chocó, en la que la autora ha jugado un papel indudable. La importancia de ese proyecto reside no solo en que ha logrado descentrar el conocimiento de un eje profesional para ubicarlo en un trabajo mancomunado entre intelectuales de todo tipo en la comunidad, en una zona del país conservadoramente vista como alejada de la "civilización", sino que a tono con ese descentramiento ha ido encontrando formas de leer y entender saberes aglutinantes de los grupos humanos hilando el lugar del cuerpo en ese conocimiento. Este texto de Ana María Arango Melo trenza esa experiencia en torno a un debate sobre el papel del arte en sociedad. Con "La música reggae en Panamá. Breve reseña histórica” estamos en el candente terreno de una música popular, tremendamente incomprendida y sobre la cual se encarnizan juicios a menudo racistas y clasistas, en abierto desconocimiento de preguntas como ¿qué papel cumplen estos géneros entre quienes los componen, los difunden y los danzan?, ¿qué valores colectivos vehiculan?, ¿cómo y dónde 
surgieron?, ¿al calor de qué contextos? En suma: ¿de qué hablan y para quiénes? (aunque, a decir verdad, el prejuicio es cierto para casi toda forma de oralidad, en tanto su exclusión de la esfera de lo cognoscible correspondió a un emparejamiento entre la escritura, nociones de civilización muy Blancas que corrían, al menos en Colombia, parejas a cuestiones geográficas). El trabajo de Guillermina Itzel de Gracia en este artículo es proveer una serie de hilos que dan sentido a los inicios de una industria musical panameña, conectada con lugares del Gran Caribe, pero también, en razón del funcionamiento de la industria musical e incluso de historias comerciales, con lugares como Buenaventura, en el Pacífico Sur colombiano. Por su parte, David Lara Ramos, con "Conflicto armado y transformación cultural", nos pone de frente la pregunta: ¿qué ocurre con una tradición musical local (de los Montes de María, en este caso), una tradición como la de la tambora, cuando sus compositores ven asediado su territorio? ¿Qué ocurre con esos compositores y compositoras? Y esto en el entendido de que la música no es meramente un escenario del disfrute, sino un foco de tensión a través del cual las acciones violentas de los grupos armados hallan denuncia y registro, una memoria en tensión. Como representante musical de algunas de las figuras más destacadas de la tambora en Colombia, David Lara Ramos ha estado inmerso en el territorio y su labor se encamina paralelamente a dar a conocer estas vo-ces (con lo que ello implica) y a la vez explorar ese tejido sutil y delicado del papel de la música en terrenos en conflicto. Estos tres artículos plantean entradas a tres manifestaciones distintas de la oralidad (musical, si queremos): en el escenario religioso, más allá de los ensalmos y cantos; en el escenario de un colectivo transformado por su quehacer, más allá de la juerga y más bien hacia la reflexión corpo-musical, y en el escenario de músicas tradicionales, con preguntas sobre la tradición, su fragilidad y su fortaleza enlazada a la memoria o a luchas sociales, en contextos acotados por la necesidad o por la guerra. Los dos artículos siguientes se concentran en el plano literario. "Oralidad o escritura del Ser", de Malissa Conseil, hace una lectura detallada de pasajes de Changó el gran putas, para sustentar cómo aparecen en esta novela ya canónica voces de los ancestros, cómo aún en lo escrito y sin recurrir a imitaciones del habla "Negra", por ejemplo, Manuel Zapata Olivella logra entreverar voces invisibles en una matriz colonial, logra darles un espacio de constitución de los sujetos. Por el actual régimen bibliométrico, es poco común la publicación de textos que son "close reading"; sin embargo, creemos que tienen un valor didáctico grande para quien desee acercarse a las sutilezas procedimentales de la crítica literaria con una herramienta sencilla, que fue común en otras escuelas, y que permite explorar, en este caso, una densidad ontológica de toda relevancia cuando de conocimientos subyugados (invisibilizados) se trata. En una vena similar, Eduardo Silva Peña, en "Las matronas y los usos políticos del sheshand en dos historias (ficcionales) sobre la isla de San Andrés", se concentra sobre los mecanismos y sentidos del chisme o sheshand, en textos de factura literaria: una obra de teatro y unos pasajes de Los pañamanes, de Fanny Buitrago. El valor de este texto reside en su aliento comparativo, entre dos momentos históricos de la isla, cuajados sobre dos autoras en extremo distintas: una dramaturga, isleña, y una narradora continental. Su propósito: rastrear un poder potencial del chisme, que en parte por los sujetos a los que se atribuye (mujeres) y en parte por su modo de circulación subrepticia, puede codificar memorias y resistencias sociales imprevistas. La entrevista de Victorien Lavou al autor de La palabre : Une juridiction de la parole, Jean Godefroy Bidima, nos devuelve al comienzo, a asuntos epistemológicos que están en el corazón de las dispu-tas atinentes a la oralidad. La entrevista pone de presente mecanismos de negociación del mundo que permean los códigos de sociedades enteras, africanas, aunque nosotros podamos reconocer en algunas 
de sus afirmaciones la presencia de mecanismos similares en el Palabrero o en mediadores de palabra en comunidades colombianas. Este libro, escrito originalmente en francés y traducido al inglés como Law and the Public Sphere in Africa abre canales a la comprensión de formas políticas radicalmente otras, y en especial, con mucha fuerza, busca hacerlas inteligibles, con lo que su validez pueda ser más nítida a ojos occidentales. Para el propósito de este número, esta entrevista es fundamental, pues si reconocemos que los estudios sobre la oralidad (al menos para el campo de la crítica literaria) siguen nutriéndose de reiteradas menciones, casos y ejemplos contextual que alimenta el poder de la oralidad en África, el modo como las distintas artes están embebidas en el intercambio oral (sea religioso, artístico o comercial) nos parece aún bastante fragmentaria, casi un saqueo continuo, a falta de una compenetración pro-funda con la historia y las idiosincracias de ese continente. Para cerrar este volumen, hemos incluido una propuesta de aplicación pedagógica basada en la obra Vean vé, mis nanas negras. Sindy Panza de la Hoz busca traducir con este ejercicio parte de lo que elaboró y concluyó durante la realización de su tesis de maestría, basada en el libro en cuestión. Nos resulta importante esta exploración de formas de re-conexión entre el análisis literario y el aula, especialmente tratándose de esta obra donde lo oral es declaradamente el elemento clave y del contexto al que la autora dirige su ejercicio. Sería posible agregar una lista larga de los trabajos interesantísimos que se están llevando a cabo en el país y que habríamos querido ver en este número. Es una lista soñada truncada por los conflictivos tiempos de los investigadores. En cualquier caso, esperamos que este número de Oralidad-es sea de alguna utilidad para seguir ampliando la reflexión y discusión sobre manifestaciones "culturales" de la oralidad, y para que intelectuales de casi toda área se planteen preguntas sobre el papel que juega la tensión de la oralidad, por su presencia o por su ausencia, en 